\title{
Ring-opening metathesis polymerization of $N$-substituted-5-norbornene-2,3-dicarboximides in the presence of chiral additives
}

\author{
Kenichi Mizuta, Satoko Fukutomi, Kazuhiro Yamabuki, Kenjiro Onimura and Tsutomu Oishi \\ Chiral and achiral amine-functionalized norbornene monomers endo-lexo- $N-(S)-(-)-\alpha-$ methylbenzyl-5-norbornene-2,3- \\ dicarboximide (endo-/exo-(S)-MBnNDI), endo-/exo- $\mathrm{N}$-phenyl-5-norbornene-2,3-dicarboximide (endo-/exo-PhNDI) and endo-/exo- \\ $\mathrm{N}$-cyclohexyl-5-norbornene-2,3-dicarboximide (endo-/exo-CHNDI) were synthesized and polymerized using 1st Generation Grubbs \\ Catalyst, and the chiroptical properties of these polymers were studied. Specific rotations of higher $M_{\mathrm{n}}$ poly $(e n d o-(S)$-MBnNDI)s \\ were negatively large compared with those of lower $M_{\mathrm{n}}$ polymers. Using (-)-spartaine (Sp) as a chiral additive, some polymers \\ exhibited stronger chiroptical properties compared with polymers that were obtained without the chiral additive.
} Polymer Journal (2010) 42, 534-539; doi:10.1038/pj.2010.38; published online 19 May 2010

Keywords: 5-norbornene-2,3-dicarboximide; chiral; methylbenzyl; ring-opening metathesis polymerization; ruthenium initiator; spartaine

\section{INTRODUCTION}

Ring-opening metathesis polymerization (ROMP) using Grubbs-type catalysts is a reaction that is known for its usefulness in forming linear and high-molecular-weight polymers. For this reason, this area has recently been a subject of intense research. Ruthenium-based systems effectively catalyze ROMP, even in aqueous systems or in the presence of other protic functional groups, including alcohols and carboxylic acids. ${ }^{1}$ In these polymers, functional groups are aligned along the polymer backbone, and polymer properties are often influenced by the specific character of these side chains. Because of this, a variety of materials with a wide range of properties and applications can be synthesized using ROMP. ${ }^{2}$ In addition, if the alignment of the side chain can be controlled, the obtained polymer might be synthesized to include specific features, such as a helical structure or liquid crystalline properties.

The ROMP of functionalized norbornene monomers has been particularly studied. The advantages of this system are that the monomers can be easily synthesized using the Diels-Alder reaction, and the ROMP of monomers exhibits a high reactivity and high functional-group tolerance. Tlenkopatchev and co-workers produced $\mathrm{N}$-substituted-5-norbornene-2,3-dicarboximides (RNDIs) with cyclic alkyl or aromatic groups, and the obtained poly(RNDI)s exhibited superior chemical properties, including a high glass transition temperature and high thermal stability. ${ }^{3}$

Optically active polymers have been attracting a great deal of attention because of their wide applicability in asymmetric catalysis, optical recognition and biological mimicry. Okamoto and co-workers ${ }^{4,5}$ reported that highly isotactic and helical polymers might be obtained using an optically active compound as an initiator, reaction solvent, chiral inducer or comonomer. Helical polymers often exhibit a high chiral-recognition ability toward various types of racemic compounds when they are used as a chiral stationary phase in high-performance liquid chromatography. This ability is not limited to configurational chirality; it also includes helical chirality. ${ }^{6}$

The stereospecific ROMP of cycloolefins has been studied in detail for many years. ${ }^{7,8}$ In the case of ring-opened poly(cycloolefin), there are three different steric structural orientations that define the polymer backbone, namely, head-head/head-tail/tail-tail, cis/trans and meso/ racemo. Tsunogae and co-workers ${ }^{8}$ have reported on the properties of tactic and atactic hydrogenated ring-opened poly(endo-dicyclopentadiene)s and features of tungsten imido/phenolate-catalyzed stereoselective ROMP. In addition, Grubbs et al. ${ }^{9}$ and Hoveyda and co-workers ${ }^{10}$ reported chiral ruthenium catalysts that are useful in efficient and highly selective asymmetric cross- and ring-opening metathesis reactions. However, to the best of our knowledge, only a few examples have been reported involving the use of chiral ruthenium catalysts for $\mathrm{ROMP}^{11}$ and there are no reports of enantioselective asymmetric ROMP reactions.

Buchmeiser et al. ${ }^{12}$ and Masuda and co-workers ${ }^{13}$ reported that amino acid-functionalized polynorbornenes show optical resolution abilities, but they do not control the configuration and tacticities of the obtained polymers. In this study, we intended to control the conformation of polymers using only chiral additives. Hexacoordinated bis-( $N$-donor ligand) complex structures have already been 


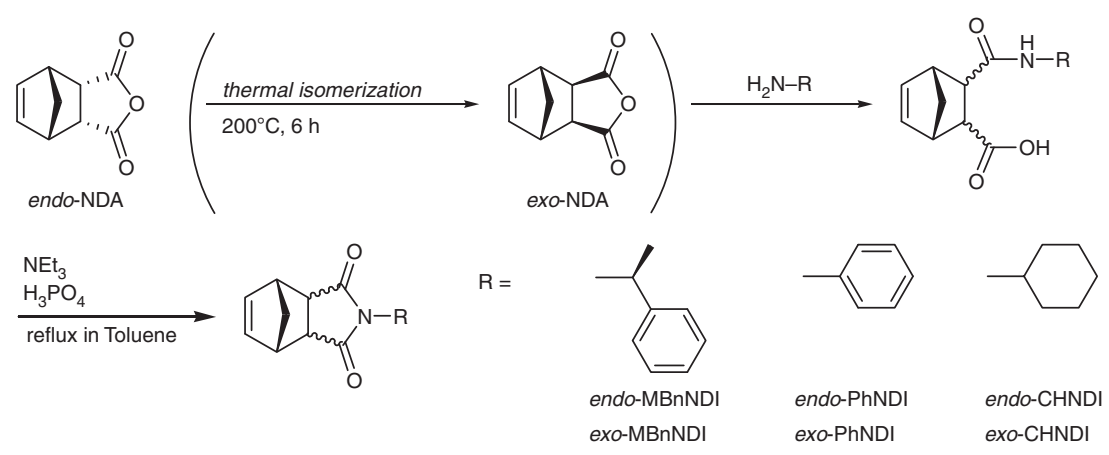

Scheme 1 Synthesis of RNDIs.<smiles>CC1CC2C=CC1C1C(=O)N(P)C(=O)C21</smiles><smiles>CC(C)(C)C1CC(C(F)(F)F)[C@H]2C(=O)N(P)C(=O)[C@H]12</smiles><smiles>Cc1ccc(-c2ccccc2)c(C(C)c2ccc(Br)cc2)c1</smiles>

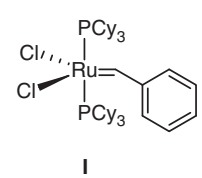
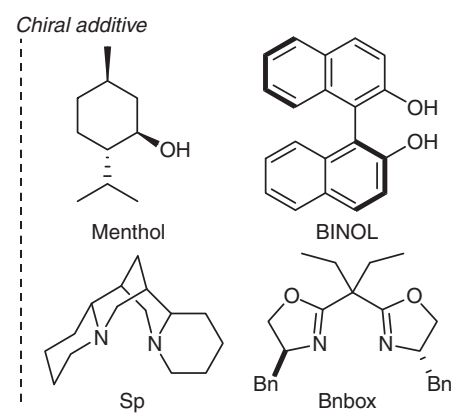

Scheme 2 Ring-opening metathesis polymerization of endo-/exo-RNDIs in the presence of chiral additives.

reported, ${ }^{14}$ and the 3rd Generation Grubbs Catalyst can be easily prepared by adding an excess of 3-bromopyridine to the 2nd Generation Grubbs Catalyst, ${ }^{15}$ but these catalysts all use amines that are not chiral. If chiral additives coordinate to 1st Generation Grubbs catalyst and the stereospecific ROMP is successful, the obtained polymer has the potential to exhibit a highly ordered structure, high optical activity and chiral recognition ability. Furthermore, these polymers also have high glass transition temperatures and show high thermal stability.

Therefore, we synthesized cyclohexyl, phenyl and $\alpha$-methylbenzylfunctionalized achiral and chiral RNDIs. These monomers were polymerized using the 1st Generation Grubbs catalyst in the presence of chiral additives (Schemes 1 and 2). The success of these reactions and the optical activities of the obtained polymers were investigated.

\section{EXPERIMENTAL PROCEDURE}

\section{Measurements}

${ }^{1} \mathrm{H}$ nuclear magnetic resonance (NMR) spectra were recorded using tetramethylsilane as an internal standard in $\mathrm{CDCl}_{3}$ on a JEOL (Tokyo, Japan) EX-270 spectrometer. Specific rotations $\left([\alpha]_{435}\right)$ were measured using a JASCO (Tokyo, Japan) P-1030 digital polarimeter. The number- and weight-average molecular weights $\left(M_{\mathrm{n}}\right.$ and $\left.M_{\mathrm{w}}\right)$ of polymers were determined by gel permeation chromatography on CROMATOPAC C-R7A Plus (LC-10AS, CTO-2A, SPD-10A, JASCO OR-990) equipped with polystyrene gel columns (HSG-40G, HSG-20H, HSG-15H and HSG-10H) and using tetrahydrofuran (THF) as an eluent at a flow rate of $1.0 \mathrm{ml} \mathrm{min}^{-1}$. The system was calibrated using polystyrene standards at $50^{\circ} \mathrm{C}$. Circular dichroism (CD) and ultraviolet visible spectra were recorded on a JASCO J-805 spectropolarimeter.

\section{Materials}

Unless otherwise stated, reagents were purchased from commercial suppliers and used without purification. (S)-(-)- $\alpha$-methylbenzylamine and $(-)$-spartaine $(\mathrm{Sp})$ were purified by Kugelrohr distillation. Exo-5-Norbornene2,3-dicarboximide ${ }^{16}$ (exo-NDA) and (4S)-2,2'-(1-Ethylpropylidene)bis[4- (1-phenylethyl)-4,5-dihydrooxazole $]^{17}$ (Bnbox) were prepared according to methods in literature. The THF and $\mathrm{CH}_{2} \mathrm{Cl}_{2}$ used in polymerization reactions were distilled using standard procedures.

\section{Monomer synthesis}

Our synthetic route to the desired monomer is shown in Scheme 1.

Synthesis of endo-(S)-MBnNDI. Endo-5-Norbornene-2,3-dicarboxylic anhydride $(15 \mathrm{~g}, 88 \mathrm{mmol})$ was dissolved in $100 \mathrm{ml}$ ethyl acetate. A solution of $8.9 \mathrm{~g}$ (73 mmol) of $(S)-(-)-\alpha$-methylbenzylamine in $150 \mathrm{ml}$ ethyl acetate was added dropwise to the stirring solution of endo-5-Norbornene-2,3-dicarboxylic anhydride and the reaction mixture was stirred at $0{ }^{\circ} \mathrm{C}$ for $3 \mathrm{~h}$. The reaction mixture was then washed several times with water and concentrated. The obtained solid was washed with diethyl ether and then dried to afford $17 \mathrm{~g}(60 \mathrm{mmol})$ of amic acid. Amic acid $(14 \mathrm{~g}, 50 \mathrm{mmol})$, phosphoric acid $(0.6 \mathrm{ml}, 10 \mathrm{mmol})$ and triethylamine $(14 \mathrm{ml}, 100 \mathrm{mmol}$ ) were then dissolved in $200 \mathrm{ml}$ toluene, heated at reflux for $90 \mathrm{~min}$ in a flask equipped with a Dean-Stark trap and then cooled to room temperature. The reaction mixture was then concentrated and again diluted in ethyl acetate and this solution was washed with $\mathrm{HCl}$ aq. $(\mathrm{pH}=2)$. The organic layer was dried over magnesium sulfate, concentrated and purified by column chromatography (silica gel, acetate $/ n$-hexane $(\mathrm{v} / \mathrm{v}=3 / 1))$ to obtain endo- $N-(S)-(-)-\alpha$-methylbenzyl-5-norbornene-2,3-dicarboximide (endo-(S)MBnNDI) as a white solid in $63 \%$ yield with an m.p. of $68^{\circ} \mathrm{C}$.

$[\alpha]_{435}$ (r.t., $c=0.1 \mathrm{~g}$ per $100 \mathrm{ml}, l=10 \mathrm{~cm}$, in THF) $=-99.4^{\circ}$.

${ }^{1} \mathrm{H}$ NMR $\left(270 \mathrm{MHz}, \mathrm{CDCl}_{3}\right): \delta$ (p.p.m.) $=7.40-7.20$ (m, 5H, phenyl), $5.93(\mathrm{ddd}, 2 \mathrm{H},-\mathrm{CH}=\mathrm{CH}-), 5.24(\mathrm{q}, 1 \mathrm{H},>\mathrm{CH}-\mathrm{N}<), 3.40-3.31(\mathrm{~m}, 2 \mathrm{H}$, $2 \times>\mathrm{CH}-\mathrm{C}=\mathrm{O}), \quad 3.16-3.18(\mathrm{~m}, 2 \mathrm{H} .2 \times-\mathrm{CH}<), 1.71-1.47(\mathrm{~m}, 3+2 \mathrm{H}$, $-\mathrm{CH}_{3}$, bridge position).

Other monomers were synthesized in a manner similar to the synthesis of endo-(S)-MBnNDI, described above.

Synthesis of endo-(RS)-MBnNDI. Endo-N-(RS)- $\alpha$-methylbenzyl-5-norbornene-2,3-dicarboximide (endo-(RS)-MBnNDI) was synthesized using (RS)$\alpha$-methylbenzylamine and was obtained as a white solid in $55 \%$ yield with an m.p. of $68^{\circ} \mathrm{C}$. 
${ }^{1} \mathrm{H}$ NMR $\left(270 \mathrm{MHz}, \mathrm{CDCl}_{3}\right): \delta$ (p.p.m. $)=7.40-7.20(\mathrm{~m}, 5 \mathrm{H}$, phenyl), 5.93 (ddd, $2 \mathrm{H},-\mathrm{CH}=\mathrm{CH}-$ ) $, 5.24(\mathrm{q}, 1 \mathrm{H},>\mathrm{CH}-\mathrm{N}<), 3.40-3.31(\mathrm{~m}, 2 \mathrm{H}$, $2 \times>\mathrm{CH}-\mathrm{C}=\mathrm{O}), 3.16-3.18(\mathrm{~m}, 2 \mathrm{H} .2 \times-\mathrm{CH}<), 1.71-1.47(\mathrm{~m}, 3+2 \mathrm{H}$, $-\mathrm{CH}_{3}$, bridge position).

Synthesis of exo-(S)-MBnNDI. Exo-N-(S)-(-)- $\alpha$-methylbenzyl-5-norbornene2,3-dicarboximide (exo-(S)-MBnNDI) was synthesized using exo-NDA and obtained as a colorless oil in $72 \%$ yield.

$[\alpha]_{435}$ (r.t., $c=0.1 \mathrm{~g}$ per $100 \mathrm{ml}, l=10 \mathrm{~cm}$, in THF) $=-115.5^{\circ}$.

${ }^{1} \mathrm{H}$ NMR $\left(270 \mathrm{MHz}, \mathrm{CDCl}_{3}\right): \delta$ (p.p.m.) $=7.48-7.21$ (m, 5H, phenyl), 6.30 $6.23(\mathrm{~m}, 2 \mathrm{H},-\mathrm{CH}=\mathrm{CH}-), 5.38(\mathrm{q}, 1 \mathrm{H},>\mathrm{CH}-\mathrm{N}<), 3.28-3.19(\mathrm{~m}, 2 \mathrm{H}$. $2 \times-\mathrm{CH}<), 2.64-2.57(\mathrm{~m}, 2 \mathrm{H}, 2 \times>\mathrm{CH}-\mathrm{C}=\mathrm{O}), 1.80\left(\mathrm{~d}, 3 \mathrm{H},-\mathrm{CH}_{3}\right)$, $1.50-1.10(\mathrm{~m}, 2 \mathrm{H}$, bridge position).

Synthesis of endo-PhNDI. Endo-N-Phenyl-5-norbornene-2,3-dicarboximide (endo-PhNDI) was obtained as a white solid in 53\% yield with an m.p. of $141-142{ }^{\circ} \mathrm{C}$.

${ }^{1} \mathrm{H}$ NMR $\left(270 \mathrm{MHz}, \mathrm{CDCl}_{3}\right): \delta$ (p.p.m.) $=7.49-7.10$ (m, 5H, phenyl), 6.29-6.25 (m, 2H, $-\mathrm{CH}=\mathrm{CH}-), 3.54-3.48(\mathrm{~m}, 2 \mathrm{H}, 2 \times>\mathrm{CH}-\mathrm{C}=\mathrm{O})$, 3.45-3.41 (m, 2H. $2 \times-\mathrm{CH}<$ ), 1.82-1.58 (m, 2H, bridge position).

Synthesis of exo-PhNDI. Exo-N-Phenyl-5-norbornene-2,3-dicarboximide (exo-PhNDI) was obtained as a white solid in $77 \%$ yield with an m.p. of $198-201{ }^{\circ} \mathrm{C}$.

${ }^{1} \mathrm{H}$ NMR $\left(270 \mathrm{MHz}, \mathrm{CDCl}_{3}\right): \delta$ (p.p.m.) $=7.52-7.23$ (m, 5H, phenyl), 6.38 $6.33(\mathrm{~m}, 2 \mathrm{H},-\mathrm{CH}=\mathrm{CH}-)$, 3.44-3.39 (m, $2 \mathrm{H} .2 \times-\mathrm{CH}<), 2.88-2.85(\mathrm{~m}, 2 \mathrm{H}$, $2 \times>\mathrm{CH}-\mathrm{C}=\mathrm{O}), 1.67-1.46$ ( $\mathrm{m}, 2 \mathrm{H}$, bridge position).

Synthesis of endo-CHNDI. Endo-N-cyclohexyl-5-norbornene-2,3-dicarboximide (endo-CHNDI) was obtained as a white solid in $46 \%$ yield with an m.p. of $160-163^{\circ} \mathrm{C}$.

${ }^{1} \mathrm{H}$ NMR $\left(270 \mathrm{MHz}, \mathrm{CDCl}_{3}\right): \delta$ (p.p.m. $)=6.10-6.06(\mathrm{~m}, 2 \mathrm{H},-\mathrm{CH}=\mathrm{CH}-)$, 3.86-3.72 $(\mathrm{m}, 1 \mathrm{H}, \quad>\mathrm{CH}-\mathrm{N}<), 3.40-3.34(\mathrm{~m}, 2 \mathrm{H}, 2 \times>\mathrm{CH}-\mathrm{C}=\mathrm{O})$, $3.18-3.15(\mathrm{~m}, 2 \mathrm{H}, 2 \times-\mathrm{CH}<), 2.13-1.06(\mathrm{~m}, 11+2 \mathrm{H}$, cyclohexyl, bridge position).

Synthesis of exo-CHNDI. Exo-CHNDI was obtained as a white solid in $36 \%$ yield with an m.p. of $135-137^{\circ} \mathrm{C}$.

${ }^{1} \mathrm{H}$ NMR $\left(270 \mathrm{MHz}, \mathrm{CDCl}_{3}\right): \delta$ (p.p.m.) $=6.29-6.26(\mathrm{~m}, 2 \mathrm{H},-\mathrm{CH}=\mathrm{CH}-)$, 4.00-3.87 (m, $1 \mathrm{H},>\mathrm{CH}-\mathrm{N}<), 3.27-3.23(\mathrm{~m}, 2 \mathrm{H}, 2 \times-\mathrm{CH}<), 2.62-2.59$ ( $\mathrm{m}, 2 \mathrm{H}, 2 \times>\mathrm{CH}-\mathrm{C}=\mathrm{O}), 2.23-1.12(\mathrm{~m}, 11+2 \mathrm{H}$, cyclohexyl, bridge position).

\section{General procedure for the synthesis of polymers}

The monomer $(0.5 \mathrm{~g})$, 1st Generation Grubbs Catalyst (0.01 equiv.) and the chiral additive ( 0.01 equiv.) were added to a Schlenk flask under an atmosphere of $\mathrm{N}_{2}$. The mixture was dissolved in dry $\mathrm{CH}_{2} \mathrm{Cl}_{2}$ and vigorously stirred.

When polymerization was completed, the reaction was quenched with ethyl vinyl ether. The solution was concentrated and the resulting solid was purified three times by reprecipitation from tetrahydrofuran (or $\mathrm{CHCl}_{3}$ ) in methanol. The polymers were dried in a vacuum oven at room temperature for 3 days.

Poly(endo-/exo-PhNDI) was soluble in chloroform and insoluble in THF, whereas poly(endo-lexo-CHNDI) and poly(endo-/exo-(S)-MBnNDI) were soluble in both chloroform and THF.

\section{RESULTS AND DISCUSSION}

Synthesis and ROMP of norbornene-based monomers

Endo-/exo-MBnNDI, PhNDI and CHNDI were synthesized by the reaction of endo-5-norbornene-2,3-dicarboxylic anhydride with $(S)$ $(-)-\alpha$-methylbenzylamine, aniline and cyclohexylamine in 63, 69 and $46 \%$ yield, respectively, and exo-5-norbornene-2,3-dicarboxylic anhydride with $(S)-(-)-\alpha$-methylbenzylamine, aniline and cyclohexylamine in 72,77 and $70 \%$ yield, respectively (Scheme 1). The ROMP of the monomers was carried out in $\mathrm{CH}_{2} \mathrm{Cl}_{2}$ using the 1st Generation Grubbs Catalyst (Scheme 2). The progress of polymerization was confirmed by ${ }^{1} \mathrm{H}$ NMR spectroscopy. Representative ${ }^{1} \mathrm{H}$ NMR spectra of endo-(S)-MBnNDI and poly(endo-(S)-MBnNDI) are shown in Figure 1, and the cis-contents are summarized in Table 1. The ciscontents in poly(exo-PhNDI), poly(endo-CHNDI) and poly(exoCHNDI) did not differ with the use of different chiral additives. In poly(endo-MBnNDI), poly(exo-MBnNDI) and poly(endo-PhNDI), cis-contents were not determined because of overlapping integration.

Table 1 cis-Contents of poly(RNDI)s obtained in the presence of chiral additives

\begin{tabular}{lcccc}
\hline & \multicolumn{4}{c}{ cis-contents $^{\mathrm{a}}$ (\%) } \\
\cline { 2 - 5 } poly(RNDI) & - & MT & BINOL & $S p$ \\
\hline poly(exo-PhNDI) & 16 & 18 & 18 & 14 \\
poly(endo-CHNDI) & 40 & 39 & 39 & 35 \\
poly(exo-CHNDI) & 21 & 25 & 21 & 20 \\
\hline
\end{tabular}

${ }^{\text {aCalculated by }}{ }^{1} \mathrm{H}$ nuclear magnetic resonance integration.

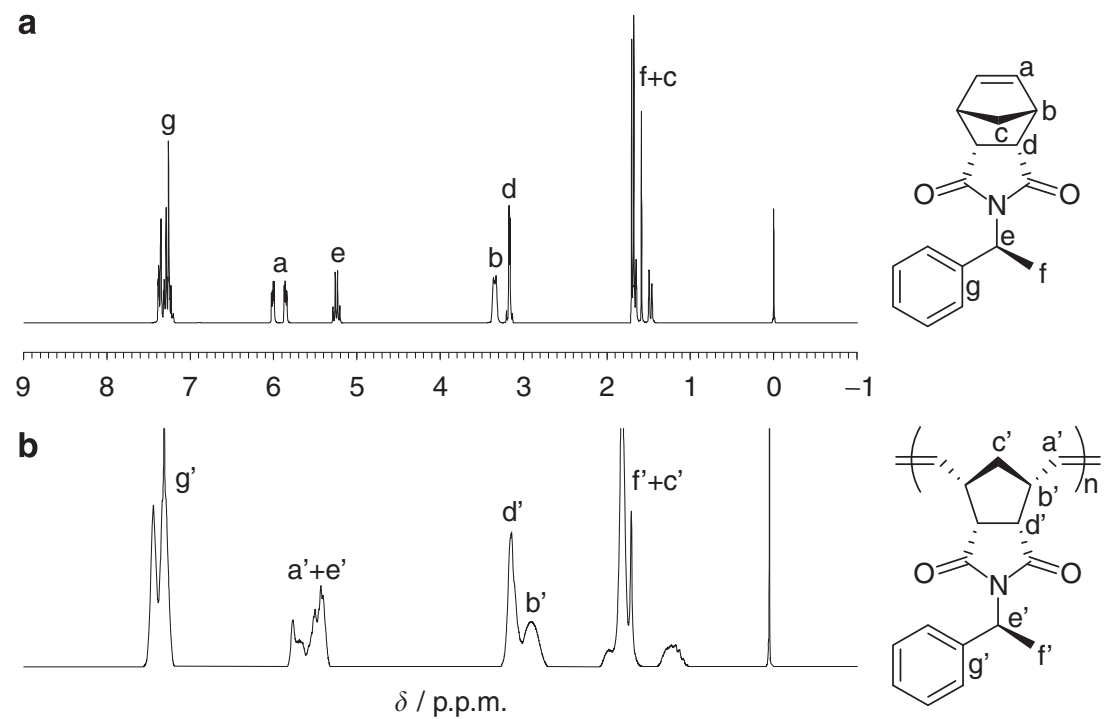

Figure $1{ }^{1} \mathrm{H}$ NMR spectra of (a) poly(endo-(S)-MBnNDI) and (b) endo-(S)-MBnNDI. 
Table 2 Ring-opening metathesis polymerization of endo-(S)MBnNDI in $\mathrm{CH}_{2} \mathrm{Cl}_{2}{ }^{\mathrm{b}}$ at room temperature

\begin{tabular}{lccccc}
\hline Entry & Time $(h)$ & Yield $(\%)$ & $M_{n}{ }^{\mathrm{d}}$ & $M_{w} / M_{n}{ }^{\mathrm{d}}$ & {$[\alpha]_{435^{\mathrm{e}}}$ (deg.) } \\
\hline 1 & 2 & 7 & 1700 & 1.20 & -115.4 \\
2 & 6 & 23 & 4100 & 1.15 & -132.7 \\
3 & 24 & 71 & 13000 & 1.14 & $-136.5^{\mathrm{f}}$ \\
4 & 48 & 70 & 16000 & 1.13 & -139.0 \\
5 & 72 & 65 & 13000 & 1.60 & -134.1 \\
\hline
\end{tabular}

Abbreviations: GPC, gel permeation chromatography; THF, tetrahydrofuran. ${ }^{\mathrm{a}} 0.5 \mathrm{~g} ;[\alpha]_{435}=-99.4^{\circ}$ in THF, $[\mathrm{M}] /[$ Cat. $]=100$.

$1.7 \mathrm{ml}$

"Methanol insoluble polymer.

GPC analysis in THF with polystyrene calibration standards.

${ }^{\mathrm{e}} \mathrm{C}=0.1 \mathrm{~g}$ per $100 \mathrm{ml}, l=10 \mathrm{~cm}$, THF.

$c=1.0 \mathrm{~g}$ per $100 \mathrm{ml}, l=10 \mathrm{~cm}$, THF.

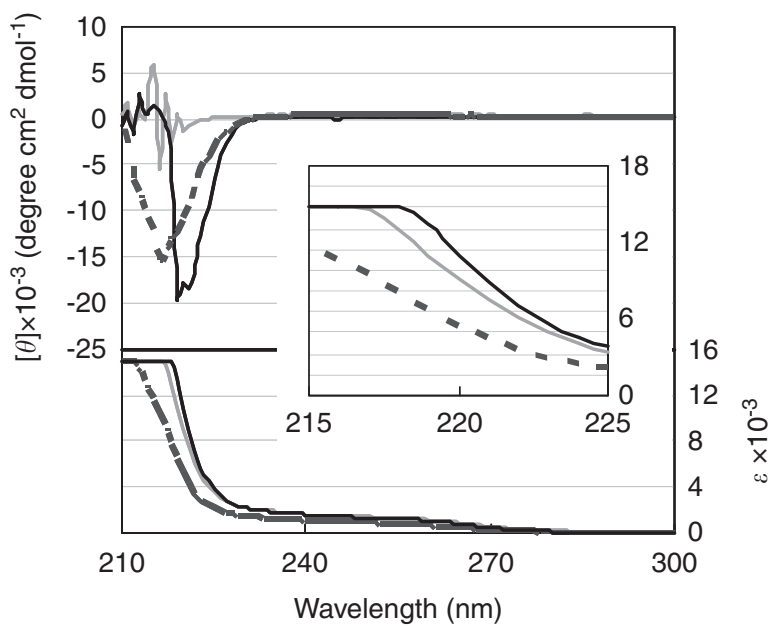

Figure $2 \mathrm{CD}$ and ultraviolet spectra for endo-(S)-MBnNDI (dashed line), poly(endo-(RS)-MBnNDI)) obtained after $48 \mathrm{~h}$ (gray line) and poly(endo-(S)$\mathrm{MBnNDI})$ ) obtained after $48 \mathrm{~h}$ (black line).
The results of the ROMP reaction of endo-(S)-MBnNDI at different reaction times are summarized in Table 2. High-molecular weight $\left(M_{\mathrm{n}}\right)$ and narrow polydispersity index (PDI) were observed as polymerization time increased (Table 2, entries $1-4$ ). When polymerization was allowed to continue for $48 \mathrm{~h}$, a polymer with high $M_{\mathrm{n}}$ (16000) and narrow PDI (1.13) was obtained. After $20 \mathrm{~h}$ of polymerization, however, livingness of polymerization decreased gradually, as a result which, the $M_{\mathrm{n}}$ and PDI values were uncontrolled for polymers that were allowed to react for longer periods, $72 \mathrm{~h} \quad\left(M_{\mathrm{n}}=13000\right.$, $\mathrm{PDI}=1.60)$, compared with those that were allowed to react for $24 \mathrm{~h}$ $\left(M_{\mathrm{n}}=13000,1.14\right.$ of PDI) or $48 \mathrm{~h}\left(M_{\mathrm{n}}=16000,1.13\right.$ of PDI) (Table 2, entries 3-5).

The specific rotations of the obtained polymers were negatively larger compared with those of the monomer. The higher $M_{\mathrm{n}}$ and narrow PDI polymers also exhibited negative specific rotations (Table 2). In addition, the CD and ultraviolet spectra of the polymer were shifted to longer wavelengths compared with those of the monomer and achiral poly(endo- $(R S)-\mathrm{MBnNDI}) \quad\left(M_{\mathrm{n}}=7700\right.$, $\mathrm{PDI}=1.24)$. The $\mathrm{CD}$ intensity also increased on polymerization (Figure 2). These results suggest that the structure of the polymer with a higher $M_{\mathrm{n}}$ and a narrow PDI was controlled by the asymmetric side chain.

ROMP of RNDIs in the presence of chiral additive

At first, we carried out the ROMP of endo-(S)-MBnNDI at $80{ }^{\circ} \mathrm{C}$ in $l$-menthol to investigate the effects of optically active additives. This system was heterogeneous because of the low solubility of the polymer in $l$-menthol. However, in the CD spectra of the polymers that were obtained in $l$-menthol, the cotton effect at $220 \mathrm{~nm}$ was slightly changed from that of the polymers that were obtained in $\mathrm{CH}_{2} \mathrm{Cl}_{2}$ $(219,221 \mathrm{~nm})$. This change could occur if the conformation of the polymer was controlled by ROMP using the optically active additive.

The results of the ROMP of endo-isomers in the presence of chiral additives are summarized in Table 3 . The polymerization reactions were carried out in $\mathrm{CH}_{2} \mathrm{Cl}_{2}$ so that they are homogeneous. Polymerization of endo-CHNDI required heating because of the system's low

Table 3 Ring-opening metathesis polymerization of endo-RNDI in the presence of chiral additive

\begin{tabular}{|c|c|c|c|c|c|c|c|c|c|}
\hline Entry & Monomera & Chiral additive ${ }^{\mathrm{b}}$ & Solvent (ml) & Temp. $\left({ }^{C}\right)$ & Time $(h)$ & Yieldc (\%) & $M_{n}^{d}$ & $M_{w} / M_{n}^{d}$ & {$[\alpha]_{435^{\mathrm{e}}}$ (deg.) } \\
\hline 1 & (S)-MBnNDI & - & $\mathrm{CH}_{2} \mathrm{Cl}_{2}$ (1.7) & r.t. & 48 & 54 & 16000 & 1.13 & -139.0 \\
\hline 2 & (S)-MBnNDI & Bnbox & $\mathrm{CH}_{2} \mathrm{Cl}_{2}$ (1.5) & r.t. & 48 & 54 & 10000 & 1.10 & -134.4 \\
\hline 3 & (S)-MBnNDI & Menthol & $\mathrm{CH}_{2} \mathrm{Cl}_{2}$ (1.5) & r.t. & 48 & 55 & 13000 & 1.12 & -138.3 \\
\hline 4 & (S)-MBnNDI & BINOL & $\mathrm{CH}_{2} \mathrm{Cl}_{2}$ (1.5) & r.t. & 48 & 50 & 11000 & 1.25 & -135.6 \\
\hline 5 & (S)-MBnNDI & Sp & $\mathrm{CH}_{2} \mathrm{Cl}_{2}$ (1.5) & r.t. & 48 & 56 & 11000 & 1.08 & -161.5 \\
\hline 6 & PhNDI & - & $\mathrm{CH}_{2} \mathrm{Cl}_{2}$ (1.5) & r.t. & 48 & 69 & $17000^{f}$ & $1.35^{f}$ & - \\
\hline 7 & PhNDI & Bnbox & $\mathrm{CH}_{2} \mathrm{Cl}_{2}$ (1.5) & r.t. & 48 & 73 & $17000^{f}$ & $1.35^{f}$ & $-2.9^{g}$ \\
\hline 8 & PhNDI & Menthol & $\mathrm{CH}_{2} \mathrm{Cl}_{2}$ (1.5) & r.t. & 48 & 63 & ND & ND & $0.9 \mathrm{~g}$ \\
\hline 9 & PhNDI & BINOL & $\mathrm{CH}_{2} \mathrm{Cl}_{2}$ (1.5) & r.t. & 48 & 70 & $14000^{f}$ & $1.60^{f}$ & $-0.3^{g}$ \\
\hline 10 & PhNDI & $\mathrm{Sp}$ & $\mathrm{CH}_{2} \mathrm{Cl}_{2}$ (1.5) & r.t. & 48 & 19 & $7200^{f}$ & $2.07^{f}$ & ND \\
\hline 11 & CHNDI & - & THF (1.5) & 60 & 24 & 73 & 12300 & 1.39 & - \\
\hline 12 & CHNDI & Menthol & $\mathrm{CH}_{2} \mathrm{Cl}_{2}$ (1.5) & 40 & 24 & 56 & 20000 & 1.30 & -0.2 \\
\hline 13 & CHNDI & BINOL & $\mathrm{CH}_{2} \mathrm{Cl}_{2}$ (1.5) & 40 & 24 & 63 & 12000 & 1.52 & -0.4 \\
\hline 14 & CHNDI & $\mathrm{Sp}$ & $\mathrm{CH}_{2} \mathrm{Cl}_{2}(1.5)$ & 40 & 24 & 43 & 9500 & 1.72 & -2.2 \\
\hline
\end{tabular}

Abbreviations: GPC, gel permeation chromatography; ND, not determined; Temp., temperature; THF, tetrahydrofuran; r.t., room temperature. ${ }^{\mathrm{a}} 0.5 \mathrm{~g}$.

b[Monomer]:[Ru Catalyst]:[Chiral additive]=100:1:1.

'Methanol insoluble part.

${ }^{\mathrm{d}} \mathrm{GPC}$ analysis in THF with polystyrene calibration standards.

${ }^{\mathrm{e}} \mathrm{GPC}$ a analysis in THF with polystyren $100 \mathrm{ml}, l=10 \mathrm{~cm}$, THF.

${ }^{f} \mathrm{GPC}$ analysis in $\mathrm{CHCl}_{3}$ with polystyrene calibration standards.

$\mathrm{g}_{C}=0.1 \mathrm{~g}$ per $100 \mathrm{ml}, \mathrm{l}=10 \mathrm{~cm}, \mathrm{CHCl}_{3}$. 
reactivity, whereas the polymerizations of endo-(S)-MBnNDI and endo-PhNDI proceeded well at room temperature. Poly(endo- $(S)$ $\mathrm{MBnNDI})$ s showed no difference in their CD spectra. However, when using (-)-Sp as a chiral additive, the obtained polymer exhibited a negatively large specific rotation compared with the others (Table 3, entries 1-5). The poly(endo-PhNDI) that was obtained in the presence of Sp had a low $M_{\mathrm{n}}$ and a poor yield (Table 3, entry 10).

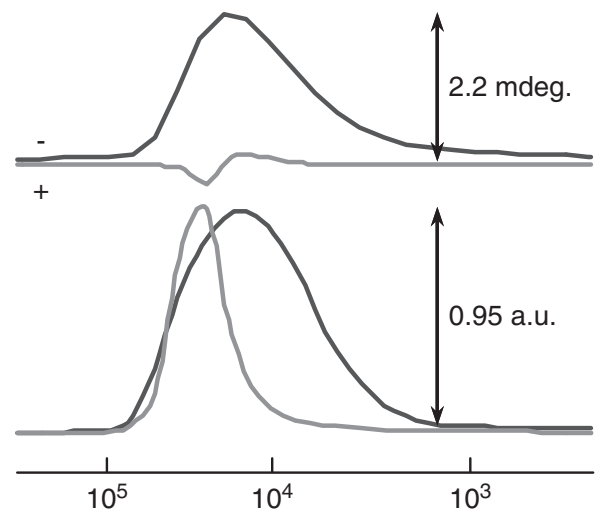

Figure 3 Gel permeation chromatography curves for poly(endo-PhNDI) (gray line) and poly(endo-PhNDI) with Sp (black line). The top chromatogram was measured using a polarimetric detector $\left(\alpha_{\mathrm{Hg}}\right)$ and the bottom using a ultraviolet detector $(254 \mathrm{~nm})$.
It seems that the Sp also weakly inhibited the 1st Generation Grubbs Catalyst, an effect similar to that reported by P'Pool and Schanz ${ }^{14}$ for 1-methylimidazole or 4-(N,N-dimethylamino)pyridine, but it is not clear why the endo-PhNDI was more greatly affected than endoMBnNDI or endo-CHNDI. Nevertheless, the achiral poly(endo$\mathrm{PhNDI}$ ) that was obtained in the presence of Sp showed a negative absorption in the gel permeation chromatography chromatogram, as measured by a polarimetric detector (Figure 3, black line). It is our view that $\mathrm{Sp}$ and the 1st Generation Grubbs Catalyst can form a Sp[Ru] complex, such as a hexacoordinated bis-( $N$-donor ligand) complex (Scheme 3), and that the chiral ligand causes enantiomorphic site control. These results support the possibility of controlling polymer structure using $\mathrm{Sp}$ as a chiral additive.

The polymerization of exo-isomers was also investigated in the presence of a chiral additive; the results are summarized in Table 4. Poly(exo-PhNDI) and poly(exo-CHNDI) with an achiral substituent showed no significant effects on the specific rotation and CD spectra. exo-Isomers are estimated to be more reactive in ROMP than endoisomers because the substituent at the norbornene endo-position hinders the coordination of the double bond to the ruthenium center of the catalyst. ${ }^{13}$ Thus, we believe that the high reactivity of exoisomers and the low steric hindrance of the substituent disturbed the enantiomorphic site control. In the $\mathrm{CD}$ spectra of poly(exo- $(S)$ $\mathrm{MBnNDI}$ ), however, the polymer obtained in the presence of $\mathrm{Sp}$ exhibited a negatively large cotton effect (Figure 4). It is very likely that the chiral and bulky substituent effectively controlled the enantiomorphic site.

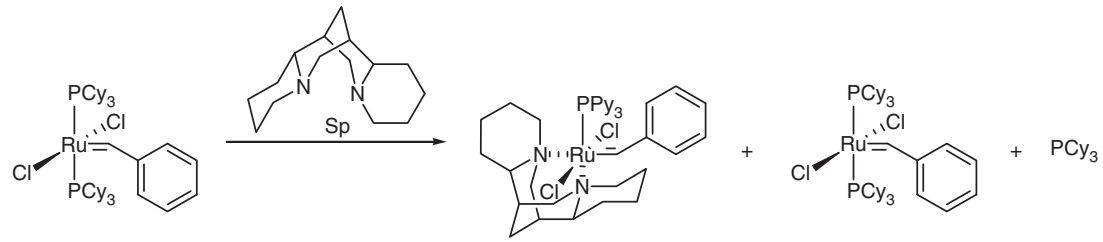

Scheme 3 Proposed Sp-[Ru] complex.

Table 4 Ring-opening metathesis polymerization of exo-RNDI in the presence of chiral additive

\begin{tabular}{|c|c|c|c|c|c|c|c|c|c|}
\hline Entry & Monomer $^{\mathrm{a}}$ & Chiral additive $^{\mathrm{b}}$ & Solvent (ml) & Temp. $\left({ }^{\circ} \mathrm{C}\right)$ & Time $(h)$ & Yield $^{\mathrm{C}}(\%)$ & $M_{n}{ }^{\mathrm{d}}$ & $M_{w} / M_{n}^{\mathrm{d}}$ & {$[\alpha]_{435}{ }^{\mathrm{e}}$ (deg.) } \\
\hline 1 & (S)-MBnNDI & - & $\mathrm{CH}_{2} \mathrm{Cl}_{2}(1.5)$ & r.t. & 48 & $>99$ & 23000 & 1.29 & -106.0 \\
\hline 3 & (S)-MBnNDI & Menthol & $\mathrm{CH}_{2} \mathrm{Cl}_{2}$ (1.5) & r.t. & 48 & $>99$ & 24000 & 1.44 & -120.6 \\
\hline 4 & (S)-MBnNDI & BINOL & $\mathrm{CH}_{2} \mathrm{Cl}_{2}$ (1.5) & r.t. & 48 & $>99$ & 23000 & 1.27 & -107.3 \\
\hline 5 & (S)-MBnNDI & $\mathrm{Sp}$ & $\mathrm{CH}_{2} \mathrm{Cl}_{2}(1.5)$ & r.t. & 48 & 97 & 24000 & 1.52 & -122.2 \\
\hline 6 & PhNDI & - & $\mathrm{CH}_{2} \mathrm{Cl}_{2}(1.5)$ & r.t. & 48 & $>99$ & $36000^{f}$ & $1.86^{f}$ & - \\
\hline 8 & PhNDI & Menthol & $\mathrm{CH}_{2} \mathrm{Cl}_{2}$ (1.5) & r.t. & 48 & 96 & $39000^{f}$ & $1.85^{f}$ & $-0.7^{g}$ \\
\hline 9 & PhNDI & BINOL & $\mathrm{CH}_{2} \mathrm{Cl}_{2}$ (1.5) & r.t. & 48 & $>99$ & $36000^{f}$ & $1.79^{f}$ & $+2.1^{\mathrm{g}}$ \\
\hline 10 & PhNDI & $\mathrm{Sp}$ & $\mathrm{CH}_{2} \mathrm{Cl}_{2}$ (1.5) & r.t. & 48 & 98 & $31000^{f}$ & $2.74^{f}$ & $+1.5^{g}$ \\
\hline 11 & CHNDI & - & THF (1.5) & 60 & 24 & ND & 20000 & 1.23 & - \\
\hline 12 & CHNDI & Menthol & $\mathrm{CH}_{2} \mathrm{Cl}_{2}$ (1.5) & 40 & 24 & 88 & 20000 & 1.29 & -0.2 \\
\hline 13 & CHNDI & BINOL & $\mathrm{CH}_{2} \mathrm{Cl}_{2}$ (1.5) & 40 & 24 & 66 & 28000 & 1.18 & -0.4 \\
\hline 14 & CHNDI & $\mathrm{Sp}$ & $\mathrm{CH}_{2} \mathrm{Cl}_{2}$ (1.5) & 40 & 24 & 66 & 23000 & 1.39 & +1.6 \\
\hline
\end{tabular}

Abbreviations: GPC, gel permeation chromatography; ND, not determined; Temp., temperature; THF, tetrahydrofuran; r.t., room temperature. a $0.5 \mathrm{~g}$.

b[Monomer]:[Ru Catalyst]:[Chiral additive]=100:1:1.

${ }^{\mathrm{c} M e t h a n o l}$ insoluble part.

${ }^{\mathrm{G}} \mathrm{GPC}$ analysis in THF with polystyrene calibration standards.

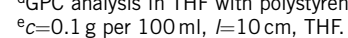

${ }^{\mathrm{f}} \mathrm{GPC}$ analysis in $\mathrm{CHCl}_{3}$ with polystyrene calibration standards.

$\mathrm{g}_{C}=0.1 \mathrm{~g}$ per $100 \mathrm{ml}, l=10 \mathrm{~cm}, \mathrm{CHCl}_{3}$. 


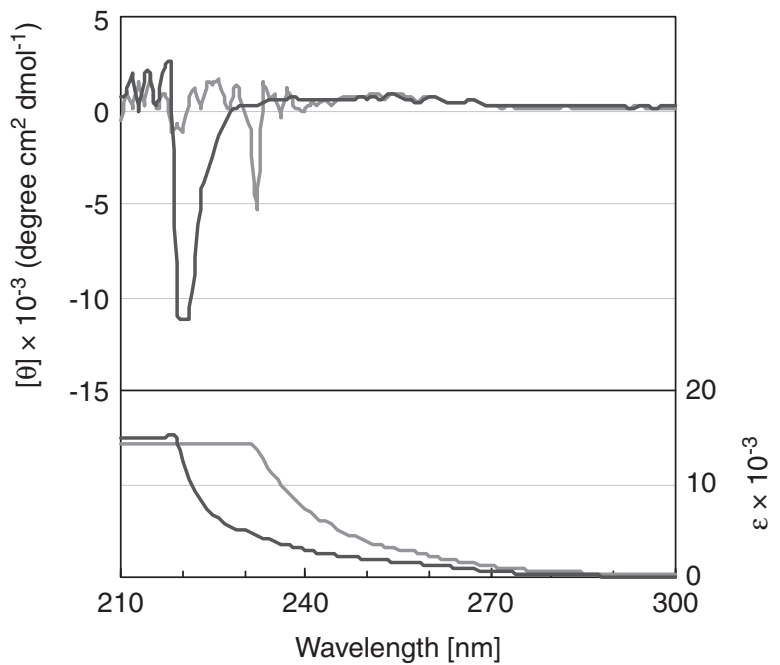

Figure $4 \mathrm{CD}$ and ultraviloet spectra for poly(exo-(S)-MBnNDI) (gray line) that was obtained in the presence of $S p$ (black line).

\section{CONCLUSION}

In this study, we described the synthesis and polymerization of chiral and achiral norbornene-2,3-dicarboximide monomers in the presence of chiral additives. The specific rotations of higher $M_{\mathrm{n}}$ poly $($ endo- $(S)$ MBnNDI)s were negatively large compared with those of lower $M_{\mathrm{n}}$ polymers. Using $\mathrm{Sp}$ as a chiral additive, poly(endo-(S)-MBnNDI) and poly(exo-(S)-MBnNDI) exhibited a negatively large specific rotation and poly(endo-PhNDI) showed a negative absorption in the gel permeation chromatography chromatograms, as measured by a polarimetric detector. These results indicate that the chiral $\mathrm{Sp}$ ligand additive caused the formation of highly ordered polymer structures.
1 Buchmeiser, M. R. Homogeneous metathesis polymerization by well-defined group VI and group VIII transition-metal alkylidenes: fundamentals and applications in the preparation of advanced materials. Chem. Rev. 100, 1565-1604 (2000).

2 Church, A. C., Pawlow, J. H. \& Wagener, K. B. Synthesis of functionalized polycarbosilanes via One-Pot ADMET polymerization-macromolecular substitution. Macromolecules 35, 5746-5751 (2002).

3 Contreras, A. P. \& Tlenkopatchev, M. A. Synthesis and gas transport properties of new high glass transition temperature ring-opened polynorbornenes. Macromolecules 35, 4677-4684 (2002)

4 Okamoto, Y., Suzuki, K. \& Yuki, H. Asymmetric polymerization of triphenylmethyl methacrylate by optically active anionic catalysts. J. Polym. Sci., Polym. Chem. Ed. 18, 3043-3051 (1980).

5 Nakano, T., Shikisai, Y. \& Okamoto, Y. Helix-sense-selective free radical polymerization of 1-phenyldibenzosuberyl methacrylate. Polym. J. 28, 51-60 (1996).

6 Nakano, T. \& Okamoto, Y. Synthetic helical polymers: conformation and function. Chem. Rev. 101, 4013-4038 (2001).

7 Grubbs, R. H. in Handbook of Metathesis Vol. 3, 143-179 (Wiley-VCH, Weinheim, 2003).

8 Hayano, S., Takeyama, Y., Tsunogae, Y. \& Igarashi, I. Hydrogenated ring-opened poly(endo-dicyclopentadiene)s made via stereoselective ROMP catalyzed by tungsten complexes: crystalline tactic polymers and amorphous atactic polymer. Macromolecules 39, 4663-4670 (2006).

9 Berlin, J. M., Goldberg, S. D. \& Grubbs, R. H. Highly active chiral ruthenium catalysts for asymmetric cross- and ring-opening cross-metathesis. Angew. Chem. Int. Ed. 45, 7591-7595 (2006).

10 Van Veldhuizen, J. J., Campbell, J. E., Giudici, R. E. \& Hoveyda, A. H. A readily available chiral Ag-based $\mathrm{N}$-heterocyclic carbene complex for use in efficient and highly enantioselective Ru-catalyzed olefin metathesis and Cu-catalyzed allylic alkylation reactions. J. Am. Chem. Soc. 127, 6877-6882 (2005).

11 Grisi, F., Costabile, C., Gallo, E., Mariconda, A., Tedesco, C. \& Longo, P. Rutheniumbased complexes bearing saturated chiral $\mathrm{N}$-Heterocyclic carbene ligands: dynamic behavior and catalysis. Organometallics 27, 4649-4656 (2008).

12 Buchmeiser, M. R., Sinner, F., Mupa, M. \& Wurst, K. Ring-opening metathesis polymerization for the preparation of surface-grafted polymer supports. Macromolecules 33, 32-39 (2000)

13 Sutthasupa, S., Sanda, F. \& Masuda, T. Ring-opening metathesis polymerization of amino acid-functionalized norbornene diamide monomers: polymerization behavior and chiral recognition ability of the polymers. Macromol. Chem. Phys. 209, 930-937 (2008).

14 P'Pool, S. J. \& Schanz, H.- J. Reversible inhibition/activation of olefin metathesis: a kinetic investigation of ROMP and RCM reactions with Grubbs' catalyst. J. Am. Chem. Soc. 129, 14200-14212 (2007).

15 Love, J. A., Morgan, J. P., Trnka, T. M. \& Grubbs, R. H. A practical and highly active ruthenium-based catalyst that effects the cross metathesis of acrylonitrile. Angew. Chem. Int. Ed. 41, 4035-4037 (2002).

16 Craig, D. The rearrangement of endo-3,6-methylene-1,2,3,6-tetrahydro-cis-phthalic anhydride. J. Am. Chem. Soc. 73, 4889-4892 (1951).

17 Denmark, S. E., Nakajima, N., Nicaise, O. J.- C., Faucher, A. \& Edwards, J. P. Preparation of chiral bisoxazolines: observations on the effect of substituents. J. Org. Chem. 60, 4884-4892 (1995). 